\title{
Using Microanalysis of Communication to Compare Solution-Focused and Client-Centered Therapies
}

\author{
Christine Tomori \\ Janet Beavin Bavelas
}

\begin{abstract}
Microanalysis in psychotherapy is the close examination of the moment-by-moment communicative actions of the therapist. This study microanalyzed demonstration sessions by experts on solutionfocused and client-centered therapies, specifically, the first 50 therapist utterances of sessions by Steve de Shazer, Insoo Kim Berg, Carl Rogers, and Nathaniel Raskin. The first analysis examined how the therapist communicated, namely, whether the therapist's contribution took the form of questions or of formulations (e.g., paraphrasing). The second analysis rated whether each question or formulation was positive, neutral, or negative. Two analysts demonstrated high-independent-agreement for both methods. Results showed that the solution-focused and clientcentered experts differed in how they structured the sessions: The clientcentered therapists used formulations almost exclusively, that is, they responded to client's contributions. Solution-focused experts used both formulations and questions, that is, they both initiated and responded to client contributions. They also differed in the tenor of their contributions:
\end{abstract}

Christine Tomori (E-mail: ctomori@gmail.com) is Community Development Coordinator at the BC Coastal Region of the Canadian Red Cross Society, Victoria, BC. She is also affiliated with the Department of Psychology, University of Victoria, Victoria, BC.

Janet Beavin Bavelas (E-mail: bavelas@uvic.ca) is Emeritus Professor of Psychology at the University of Victoria, Victoria, BC.

Journal of Family Psychotherapy, Vol. 18(3) 2007

Available online at http://jfp.haworthpress.com

(C) 2007 by The Haworth Press, Inc. All rights reserved. 
The solution-focused therapists' questions and formulations were primarily positive, whereas those of the client-centered therapists were primarily negative and rarely neutral or positive. Microanalysis can complement outcome research by providing evidence about what therapists do in their sessions. doi: 10.1300/J085v18n03_03 [Article copies available for a fee from The Haworth Document Delivery Service: 1-800-HAWORTH. E-mail address: <docdelivery@haworthpress.com> Website: <http://www.HaworthPress.com> (c) 2007 by The Haworth Press, Inc. All rights reserved.]

KEYWORDS. Solution-focused therapy, solution-focused, research, micro-analysis, communication, client-centered, client-centered therapy

Communication is the essential process of psychotherapy (Bavelas, McGee, Phillips, \& Routledge, 2000). Therapists bring to each session their theory, knowledge, experience, empathy, and intentions, but these can only have an effect through their moment-by-moment communication with their client. The most salient research on psychotherapy has been outcome research, which can provide evidence of the effectiveness of various therapeutic practices. However, outcome research still leaves open questions about what happened during the therapy sessions that may have led to change (or not). In this respect, we concur with Kazdin and Nock (2003) on the need for research on the "mechanisms of change" (i.e., on how a particular therapy might work) as a necessary complement to studies focused on whether a therapy works. Kazdin and Nock's purpose was to outline broad methodological issues of design and interpretation, rather than to discuss what the mechanisms of change might be. Even so, it is striking to us that their examples of possible change factors were predominantly inferred intrapsychic states that therapy might create "in the client" (e.g., cognitive restructuring, hope), with little emphasis on what the therapist did to effect those changes. There are several abstract references to the "therapeutic alliance" but none to the therapist's communication or actions other than a passing reference to "bonding statements of the therapist" (p. 1126). In short, we agree that it is just as important to know how therapy works as whether it works, but propose more specifically that the therapists' communicative actions are central to this question. The overt communicative actions of therapists in their sessions are also of particular interest to practicing clinicians because these are the tools they take with them into their sessions. Similarly, the observable details of communication are important for teachers and trainers because these are explicit and specifiable behaviors that novices can become aware of and seek to master (or to avoid). One way to provide an evidence base for these issues is microanalysis, which is the moment-by-moment analysis of the therapist's observable communicative actions.

In proposing that communication is the means by which therapy takes place, we do not assume that it is simply a medium for one isolated mind to convey thoughts or feelings to another. Rather, we view dialogue in therapeutic communication as co-constructive, as an ongoing process in which the participants both shape the direction and meaning of the session. Therapist and client together create the form and content of the conversation. It is therefore important to keep in mind that the therapist comes to the session with the status of an expert and therefore, arguably, has considerable inherent power to validate or even shape the nature of the problem and the solution for the client. We believe that it is better for the therapist to exercise this power deliberately rather than by default and that a close analysis of what the therapist actually does (vs. intends to do) is essential for therapists to understand fully the choices they are making in a session. In short, we need to begin to know more about exactly how the process of therapy proceeds and what the therapist contributes to it. This is the third article from our research group on how microanalysis can contribute to such knowledge (see also Bavelas et al., 2000; McGee, Del Vento, \& Bavelas, 2005).

The present research compared two strikingly different therapeutic approaches: the "client-centered or non-directive" therapy developed by Carl Rogers (e.g., Rogers, 1965; Farber, Brink, \& Raskin, 1996) and the "solution-focused" brief therapy developed by Steve de Shazer and Insoo Kim Berg (e.g., de Shazer, 1985; De Jong \& Berg, 2002). We examined teaching videos by two distinguished representatives of each approach-Steve de Shazer, Insoo Kim Berg, Carl Rogers, and Nathanial Raskin-on the assumption that such videos would best represent what each therapist wanted to convey about his or her techniques. That is, we used a "best case" approach rather than any form of sampling.

We chose to contrast these two particular therapeutic approaches for both practical and theoretical reasons. More than most other therapies, both approaches have made their practices open for examination and, essential for our purposes, have provided readily available, complete videotaped sessions for analysis. In addition, both approaches describe a fairly explicit theoretical approach to the details of communication, which is often missing or only implicit in other approaches. That is, they 
go beyond theories of the client and take a stand on therapeutic practices. Rogerian therapists aim to intervene minimally, by listening closely and limiting their contribution to paraphrasing while clients present their problems and come to their own insights into the presumed cause of those problems. They also emphasize the specific importance of conveying positive regard for the client. Solution-focused therapists intervene more deliberately, using questions that seek to identify the clients' existing resources and solutions, emphasizing strengths, and minimizing discussion of problems. It is therefore possible to assess whether these practitioners are doing what they advocate.

The present microanalysis focused on two specific aspects of these sessions. First, in what form did the therapist contribute to the dialogue? That is, were they more likely to initiate topics with questions or to wait and respond to what the client had said? Client-centered therapy emphasizes non-intervention and therefore seeks to reflect what the client is saying rather than directing it. Paraphrasing, summarizing, and reflecting are its major techniques. These contributions, technically called “formulations" (Garfinkl \& Sacks, 1970, p. 350), occur after the client's statements, where they are intended to function as a kind of mirror for what the client has said. Two typical formulations from the sessions we analyzed were the therapists' italicized responses in the following excerpts of a client-centered (CC) session:

Client: ... and ah, doomed to fail-not that I will die or anything. I think doomed to fail and to be there for children, in a positive, cheerful, warm, loving way. And being a single parent, like I will be, their support system to a large extent. And it scares me to think of their main support as being exhausted and irritated and-

Rogers: [paraphrasing client] "I just feel I may be able not be able to make it. I may be doomed to failure by the very circumstances."

Client: Right.

From a solution-focused (SF) session we have the following:

Client: Well, right now I'm dealing with a drinking problem.

de Shazer: Uh-hum.

Client: Yeah. de Shazer: $\mathrm{OK}$, and ah

Client: Sometime I drink-

de Shazer: You say, right now.

Another option for the therapist is to ask questions, that is, to request new information from the client. Functionally, a question is an utterance that requests information the therapist does not have. Although, like $\mathrm{CC}$, solution-focused (SF) therapy advocates a "not-knowing" position in which the therapist does not impose particular insights or solutions, it is much more active in seeking specific kinds of information from clients by asking questions about positive futures, current successes, and client goals. Unlike formulations, questions obviously precede the client's utterance, where they serve to direct the client's contribution onto certain topics rather than others (McGee, Del Vento, \& Bavelas, 2005). It is likely that $\mathrm{CC}$ therapists would consider questions directive and would generally prefer formulations, so we would expect CC and SF therapistsho differ in the extent to which they use formulations versus questions for their contributions to their sessions.

The second focus of this research was to investigate whether these two appribaches differ in "what" the therapist talks about, specifically, whether the content is positive, negative, or neutral. CC therapy aims to take a non idrective stance, which would lead to neutral utterances, or to convey unconditional positive regard, which would lead to positive comments. However, most SF therapists would consider CC problemfocused because of their emphasis on insight into the nature of the client's problem. In contrast, SF therapists acknowledge the client's problem but primarily emphasize positive aspects of the clients' actions or goals. We examined the utterances of the four experts to ascertain how their theoretical goals manifested in practice: Was what they said primarily "positive," "neutral," or even "negative?"

For the purpose of comparing SF and CC therapists on the form and content of their contributions, it was necessary to develop analytical tools for identifying these characteristics and to establish high interanalyst reliability. We then analyzed the first 50 therapist utterances in each session, 100 therapist utterances from each approach. The next section describes the source of the data, the operational definitions, and the reliability of the analysis. 


\section{METHOD}

\section{Data}

The data were from four videotaped therapy sessions conducted by the founders of and experts on two different therapeutic approaches. The CC sessions were by Carl Rogers (1980) and Nathaniel Raskin (1994); the SF sessions were by Steve de Shazer (1990; also transcribed in part in de Shazer (1994, pp. 246-270) and Insoo Kim Berg (1994)). The case backgrounds were as follows:

Berg: The client was an African-American teenage boy named Carl, from a low socio-economic background and attending an alternative high school for at-risk youth. His brother was just out of prison and frequently violent toward him. Berg was conducting a workshop at his high school. After the workshop, Carl approached her and disclosed that he had tried to kill himself the night before. Because this was a high-risk situation, Berg made arrangements to have a therapy session with Carl later that day.

de Shazer: The client was a 32-year-old married African-American man, from a low socio-economic background, who has a longstanding alcohol problem. He had been in several treatment programs, some of which worked for a while, but with many relapses. He was now worried about the effects of his drinking on his health.

Rogers: Sylvia was a Caucasian woman in her 30's, a recently divorced mother of two young children. She was concerned about how to support her children when they came to live with her and about whether she could work full-time and still be a good mother to her children. She was probably middle class and well educated, and she had attended a seminar with Rogers in the recent past.

Raskin: This case used an actor. "Cynthia" was a married AfricanAmerican woman, probably middle class and well educated. One night, after a social evening with friends, she and her husband started arguing. She hit him, and he hit her back. This was the first such incident, and she was concerned about what it means about her.
The analysis covered the first 50 utterances of each therapist; which corresponded to approximately 15 minutes of the beginning of each session, except for the session by Nathaniel Raskin which took an additional 15 minutes because the client spoke at length and Dr. Raskin usually responded with minimal listener responses (see definition below).

\section{Materials}

We used Broadway software (www.b-way.com) to digitize and analyze the originally videotaped sessions. The analysts also used four specially formatted transcripts and an instruction booklet to analyze the data. The written materials can be obtained from the authors.

\section{ANALYSIS}

There were two independent analysts in this study, Christine Tomori and Jesse Elterman, for the purpose of demonstrating reliability. The first analyst examined all of the data for both phases, and the second analyst examined approximately the first $75 \%$ of the data for phase I and the first $50 \%$ for phase II. There were two sequential phases of analysis: Phase I identified the kind of utterance the therapist made (e.g., formulation or question), and phase II determined the direction that the therapist took in that utterance (e.g., positive or negative). The analysis of each phase involved three broad stages. First, each analyst played the digitized therapy session, rated each utterance made by the therapist according to the instruction booklet, and recorded the rating on the formatted transcript. During analysis, he or she focused on the digitized video, including facial expressions and prosody (e.g., intonation und word stress) and used the transcript only as a guide and recording sheet. Second, the analysts compared their ratings and calculated their percentage of agreement. Third, if the analysts did not agree on some ratings, they resolved their disagreements and, if necessary, recruited " third analyst (Bavelas) to come to a final decision for each utterance.

\section{Phase I: Questions and Formulations}

In the first phase, the analysts rated each therapist's utterances ins a formulation, a question, a formulation and question, or neither a formulation nor a question. The extensive definitions and examples we 
developed for each of these ratings are available from the authors and will be summarized here.

A therapist's utterance corresponded to a speaking turn and ended when the client started to speak again. However, overlapping or interjected listener responses (e.g., "Mhm") were not separate utterances; these minimal listener responses were treated as background within the speaker's utterance. The analysts treated each therapist's utterance as a whole unit. That is, they assigned only one value to an utterance during each phase. The italicized part of the following example is a therapist's utterance:

Client: No financial support, and it's not like I will have my mother next door or something.

Rogers: You will be alone with a heavy burden and it is a sad prospect feeling.

Client: It feels sad.

Bavelas, McGee, Phillips, and Routledge (2000) credited Garfinkel and Sacks (1970, p. 350) with defining "formulations" as utterances that described, characterized, explicated, translated, summarized, or furnished the gist of what was just said. An example from our data is in italics in the following excerpt:

Client: Yeah. I guess if I really thought hard enough I could probably find some more.

Raskin: If you could dig around a little you could come up with more.

Client: Yeah, probably.

The analysts also used one or more of the following criteria to guide their decisions: (1) A formulation did not introduce new information; it restated what the client had said earlier. (Therefore, the first utterance of a session could not be a formulation because it preceded any utterance made by the client and therefore could not formulate what the client had said earlier.) (2) It was a reasonable summary of what the client had said earlier. (3) It functioned as part of grounding (e.g., Clark, 1996), that is, the therapist seemed to be demonstrating that he or she had understood the client. (4) It invited a minimal listener response (e.g., "yeah."). (5) It often began with a discourse marker such as "so. ...".

Questions are utterances that inquire about something and invite the client to reply to the therapist's inquiry, usually by providing information that the therapist does not have as given in the following example:

Berg: So, how did you manage to get to school today?

This was a question because the therapist asked the client how he was able to do something difficult, which was information that was not directly available to the therapist. A question had to meet one or more of the following criteria: (1) It requested new information, (2) The pitch became higher at the end of utterance (prosody), or (3) It invited more than a minimal listener response. However, the first criterion was more important than the others. Some formulations resemble questions syntactically or prosodically, but they are confirming understanding rather than seeking new information. For example,

Client: . . . I mean, when I was on that bus, I was just thinking, the first thing I'm going to do is go off and do something crazy like try ' $n$ ' kill myself. But then on the other hand, I kept on thinking all the people I would hurt if I do do it, you know, I wouldn't live, I wouldn't see my graduation, I wouldn't, you know, see my family grow, so those things just combined and just-

Berg: So you decided that you were going to live? It's better for you to live than die?

Client: Yeah, I went through it, but I came out of if all right.

The therapist was summarizing part of what the client had just said, not asking for new information.

Utterances that included both a minimal listener response and a question were simply questions; for example:

de Shazer: Okay. And, but there are some days you don't do any, you don't drink at all?

There were also some utterances that contained two parts, one a formulation and one a question as in the following example:

Client: I like basketball. 


\section{de Shazer: Basketball. Huh-hm. What else?}

The first part of the therapist's utterance was a formulation, the middle part was a minimal listener response, and the last part of the same utterance was a question. Therefore, the entire utterance was treated as both a formulation and question.

There were several kinds of utterances that could not be either a formulation or a question.

1. "Minimal listener responses" such as "Mhm," "yes," and "okay," even when they occurred as a separate speaking turn, were neither a formulation nor a question because they neither captured what the client had said earlier nor requested new information.

2. Words such as "I," "me," or "my" were indications that the therapist was offering his or her opinion regarding the client's situation.

The following were two examples of when a therapist was offering his or her own opinion:

Rogers: Then that's what I'd like you to discuss.

Berg: Oh my goodness!

These examples were not formulations because they were not paraphrasing what the client said earlier; rather they were explicitly adding information about what the therapist thought about the client's situation. However, the therapist could use the word "I" in their paraphrase in a way that we considered a formulation rather than an opinion:

Client: ... and ah, doomed to fail-not that I will die or anything. I think doomed to fail and to be there for children, in a positive, cheerful, warm, loving way. And being a single parent, like I will be, their support system to a large extent. And it scares me to think of their main support as being exhausted and irritated and-

Rogers: [paraphrasing client] "I just feel I may be able not be able to make it. I may be doomed to failure by the very circumstances."

\section{Client: Right.}

3. Another utterance that was neither a formulation nor a question could occur when the therapist "agreed" with the client, such as when the therapist said: "Yes you did!" or "Yes!" These utterances neither requested new information from the client nor restated what the client had said earlier; they only expressed the therapist's opinion about what the client had said earlier.

4. The therapist's giving "instructions" to a client was neither a formulation nor a question as seen in the following example:

de Shazer: So, this might seem like a somewhat strange question, but suppose that when you go home tonight and you go to bed and you go to sleep. A miracle happens and the problem that brings you here is solved. But you can't know it because it happens while you're sleeping.

Instructions such as these would be neither a formulation nor a question because the therapist was explicitly guiding the client into a particular perspective and requesting the client to imagine a novel idea or situation, rather than requesting new information from the client or formulating what the client just said.

5. Incomplete utterances by the therapists were neither a formulation nor a question as given in the following example:

$$
\text { Berg: . . . easy for you. }
$$

In this case, the utterance was not complete, so the analyst did not have enough information to rate it as a formulation or question.

\section{Reliability}

For phase I of the analysis, the analysts' achieved $80 \%$ agreement for Carl Rogers, $95 \%$ for Nathaniel Raskin, $86 \%$ for Insoo Kim Berg, and 95\% agreement for Steve de Shazer.

\section{Phase II: Positive, Negative, or Neutral Contributions}

In the second phase, the analysts classified the therapists' formulations or questions as either "positive," "negative," "both positive and negative," "neutral" (neither positive nor negative), or "not analyzable." The guiding principle for the analyst was "would this be a "positive" or "negative" direction for me if I were in this situation?" See examples of all of these options, below. The analysts ignored all utterances that they had agreed were categorized as, both formulations and questions, and as neither 
formulations nor questions. These were predominantly minimal listener responses, which could not be classified as positive, negative, or neutral.

There were four steps to guide the analyst in making these decisions. First, the analysts read the client's background information and watched the transcribed part of the digitized session. An example of background information was this summary:

The client was a teenage boy named Carl who attended an alternative high school for at-risk youth. The therapist, Insoo Kim Berg, was conducting a workshop at his high school. After the workshop, Carl approached her and disclosed that he had tried to kill himself by cutting his throat the night before. Because this was a high-risk situation, Berg made arrangements to have a therapy session with Carl as soon as possible.

It was important for analysts to have sufficient background information about the client because they often had to consider the specific nature of the problem in order to assess whether the therapist's utterance was positive or negative, given the problem. For example, when the client lived in a poor neighborhood with a high rate of unemployment, then asking in an upbeat tone, "How do you pay your bills?" was positive because it presupposed that he could and did pay them. The same question in a concerned tone to someone who was overtly worried about finances would be considered a negative question, because it presupposed that the client may not be paying them. The analysts also watched and attended to the context of the entire unfolding dialogue between the therapist and client in order to avoid losing the meaning of their dialogue.

Second, the analysts played the digitized segment and followed the dialogue with the formatted transcript. They paid close attention to the utterances made by the therapist, their prosody, and their facial expressions. This was important because a therapist could say the same utterance with a surprised or encouraging tone or with a heavy or assertive tone. A therapist could also say an utterance with negative content in a positive way prosodically, or vice versa. Therefore, when the analysts were making a decision about positive, negative, etc., they needed to make it based on both content and prosody. The analysts also attended to facial expressions during this phase because a therapist could use ambiguous words with a smile on his or her face. Based on both the words and the facial expression, the analysts might decide that the utterance was positive. Altogether, the analysts used the content, prosody, facial expressions, background information about the client, and the context of the dialogue, to decide whether the direction of the dialogue in the formulation or question would be desirable.

Third, the analysts examined each utterance the therapist made and asked: "Does this formulation or question describe a direction that would be desirable for me?" They used this guideline in the context of the client's background information; therefore, the guideline could be rephrased in this example as: "Does this formulation or question describe a direction that would be desirable for me [if I am a teenage boy who just tried to commit suicide last night]? Finally, the analysts made one of the following decisions:

1. If the analysts answered "Yes," the utterance would be a positive. For the question that Insoo Kim Berg asked Carl:

Berg: Ah, Carl, um, which what is your best subject in school?

The answer would be "yes": If I were a teenage boy who had just tried to commit suicide and I were asked a question about my best subject in school, I would like to talk about my best subject (and the question presupposes that I have one). I would consider this direction to be desirable because I would have an opportunity to talk about what is good in my life. Therefore, the direction that Berg's question took Carl would be a positive direction. Note that we did not assume that it might be clinically more important and therefore somehow positive to talk about his suicide attempt, because that is an assumption on which these therapies differ. Such an assumption also focuses on the therapist's motives in contrast to our focus on what he or she said. Our analysis was much simpler; it is positive to talk about things one does well and negative to talk about unpleasant topics.

2. If the analysts answered "No," then the utterance would be negative. Later in the same interview with Carl, Insoo Kim Berg asked about Carl's suicide attempt the night before:

Berg: O.k. I wanted to follow up on what we just started to just a little bit we didn't have much time to talk [C: right], we had five minutes to talk this morning. So, I wanted to follow up on that. You were saying that you wanted to ... you wanted to kill yourself yesterday? 
This question would be negative; If I am a teenage boy who had just tried to commit suicide the night before, I would find it very undesirable to discuss the topic. It would make me think about the feelings that were so painful I wanted to end my life. (It is important to mention here that completely avoiding any discussion about the suicide attempt would have been irresponsible and unethical).

3. If the analysts answered both "Yes" and "No," then it would be both a positive and negative utterance. This would happen when one utterance included both desirable and undesirable directions as in the following example:

Rogers: Sort of a new phase of your life, is that-It has excitement as well as dread in it I guess.

4. If the utterance was open-ended and did not commit the analysts in any direction (positive or negative), then they classified the utterance as neutral as given in the following example:

Client: I put on my happy face. Yeah, that's what I call it.

Berg: That's what you call it?

The analysts would consider this utterance, spoken in a matter-of-fact way, to be noncommittal. It had neither positive nor negative implications for the client. Notice again that the analysts did not hypothesize any deeper meanings or motivations for asking the question; they focused instead on how the client would understand it.

5. If the analyst could not resolve whether the utterance was positive or negative, he or she could call it not analyzable. This decision meant it was too difficult to rate, whereas a rating of neutral meant that the utterance did not go in either a positive or negative direction.

\section{Reliability}

For phase II of the analysis, the analysts achieved $86 \%$ agreement for Carl Rogers, $85 \%$ for Nathaniel Raskin, $100 \%$ for Insoo Kim Berg, and $90 \%$ agreement for Steve de Shazer.

\section{RESULTS}

As shown in Table 1, the two approaches differed in their use of formulations versus questions. For the $\mathrm{CC}$ therapists, 69 of their 100 utterances were formulations and only 1 was a question. The SF therapists used an equal amount of formulations and questions: 29 of their utterances were questions and 28 were formulations. The solution-focused therapists had somewhat more minimal listener responses (neither questions nor formulations).

Phase II included only the 70 formulations or questions by the $\mathrm{CC}$ therapists and the 57 of these two kinds by the solution-focused therapists. As shown in Table 2,11 of the 70 client-centered questions or formulations were in a positive direction, 4 were neutral, and 44

TABLE 1. Form of Therapist Contribution by Client-Centered versus Solution-Focused Therapists

\begin{tabular}{lccccccc}
\hline & \multicolumn{3}{c}{ Client-Centered Therapists } & \multicolumn{3}{c}{ Solution-Focused Therapists } \\
\cline { 2 - 7 } & Rogers & Raskin & Both & de Shazer & Berg & Both \\
\hline Formulations & 22 & 47 & 69 & 5 & 23 & 28 \\
Questions & 1 & 0 & 1 & 20 & 9 & 29 \\
Formulations and questions & 1 & 0 & 1 & 4 & 0 & 4 \\
Neither formulations nor & 26 & 3 & 29 & 21 & 18 & 39 \\
questions & 50 & 50 & 100 & 50 & 50 & 100 \\
Total & & & & & &
\end{tabular}

TABLE 2. Positive, Negative, or Neutral Formulations and Questions by Client-Centered and Solution-Focused Therapists

\begin{tabular}{lrrrrrr}
\hline & \multicolumn{3}{c}{ Client-Centered Therapists } & \multicolumn{3}{c}{ Solution-Focused Therapists } \\
\cline { 2 - 7 } & Rogers & Raskin & Both & de Shazer & Berg & Both \\
\hline Positive & 0 & 11 & 11 & 20 & 25 & 45 \\
Negative & 19 & 25 & 44 & 2 & 6 & 8 \\
Positive and negative & 2 & 9 & 11 & 0 & 0 & 0 \\
Neutral & 2 & 2 & 4 & 3 & 1 & 4 \\
Not analyzable & 0 & 0 & 0 & 0 & 0 & 0 \\
Total & 23 & 47 & 70 & 25 & 32 & 57 \\
\hline
\end{tabular}

Note: The main effect of therapy on positive versus negative was tested with the itallcized Irequencien. $\chi^{2}(1, N=108)=45.54, p<0.001$. 
were in a negative direction. Of the 57 solution-focused questions or formulations, 44 were in a positive direction, 5 were neutral, and 8 were in a negative direction. The Chi-square ${ }^{1}$ for the effect of therapeutic approach on positive versus negative direction was significant (see Table 2 and Figure 1).

\section{DISCUSSION}

As each would have predicted, the two approaches to therapy differed in their ratio of formulations to questions. Rogers and Raskin used primarily formulations and asked very few questions, whereas de Shazer and Berg used both equally, which meant many more questions than the CC therapists. The effect of these two forms on the client and the dialogue is likely to be different. Questions ask the client to provide new information, which the therapist does not know. They also introduce the therapist's focus and assumptions in an indirect way (McGee et al., 2005). Formulations restate what the client has already said, rather than seeking new information. They also introduce the therapist's influence, but in a different way. As Heritage and Watson (1979) pointed out, unless they are word-for-word repetitions, formulations inevitably preserve, delete, and transform elements of the other person's

FIGURE 1. Frequency of Positive versus Negative Formulations or Questions in Client-Centered (Total $N=55$ ) and Solution-Focused Therapies (Total $\mathrm{N}=53$ )

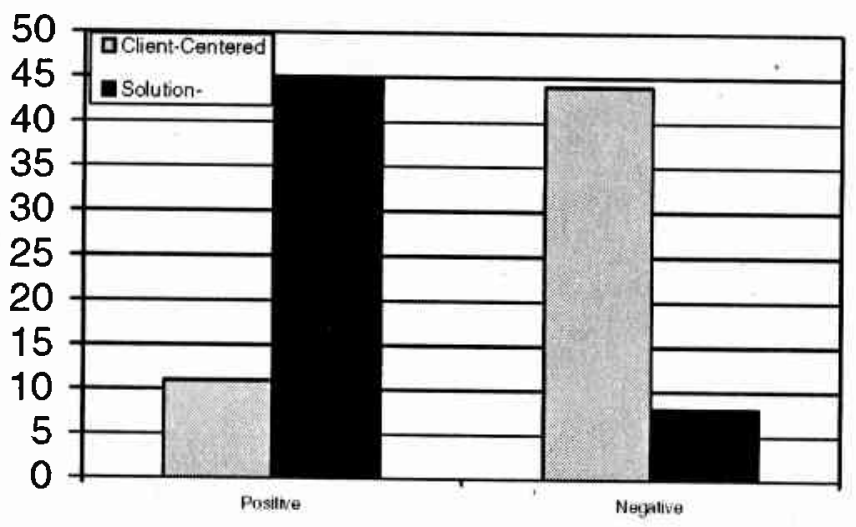

statement. Given the power and authority inherent in the therapist's position, there is a chance that the formulation will be taken by the client as the correct version of what he or she has just said. There is, therefore, some possibility that formulations can close off each of the client's contributions rather than inviting new information. As with questions, this possibility can be used for many different purposes; we are only drawing attention to their inevitable power to affect the therapeutic conversation.

As they would have predicted, the questions and formulations of de Shazer and Berg were predominantly positive. The most surprising result in this study was that those of Rogers and Raskin were not often positive, rarely neutral, and mainly negative. One might wonder whether this result could be an artifact of a difference in what the clients brought to their sessions. That is, if CC therapists aim to reflect the clients' utterances, then clients with worse problems would lead to more negative therapist utterances. However, the presenting problems in this study happened to differ in the opposite direction. Rogers' client was concerned about being a single, working mother, and Raskin's client was worried about initiating a single violent incident with her husband. Without trivializing those legitimate concerns, the SF clients presented more serious problems: de Shazer's client had long-standing drinking problem with several previous relapses, and Berg's young client was an at-risk adolescent who had just attempted to kill himself again. It appears that the possibility of positive or negative input from the therapist is always present, regardless of case details, and it is the therapist's choice that determines which direction the therapy will go in.

We have no doubt that the $\mathrm{CC}$ therapists intended their comments to be sympathetic and clarifying for their clients, but the perhaps unintended result was an overwhelmingly negative tone to their communication. De Shazer (1994, pp. 66-67) proposed an informal experiment in which the reader is to respond to the following situations:

[I]magine that you have spent the previous half-hour talking to $\mathrm{Mr}$. A about all of the problems in his life, focusing particularly on his feelings of depression. How do you feel after this half-hour?... [C] an you imagine what the client must feel like?

[Now] imagine that you have spent the previous half-hour talking to Mr. B about all of the things that have gone well in his life, focusing particularly on his feelings of success. How do you feel 
after this half-hour? . . [C]an you imagine what the client must feel like...?

Recall that we distinguished at the outset between outcome and process research. Our results suggest there are significant differences in what happens within a session in these two different therapeutic approaches. We make no claims here for what the ultimate effects of these differences would be on therapeutic outcome, but we propose that evidence-based practice should consider both process and outcome. We need to know what happened in the session(s) in order to know how to account for good (or poor) outcomes. As noted at the outset, interest in the mechanisms of change has tended to focus on changes in the clients' cognitions, emotions, or behaviors. We propose that process research must include (or even begin with) the close study of therapists' behaviors. What happens in a session, including what the therapist does, is both specific and observable. As shown here, these moment-by-moment actions may not always correspond to the approach implied by the theoretical framework or prescribed in a standardized manual.

There are several other possible future directions for microanalysis of communication in psychotherapy. The analytic tools presented here could be used to compare any other approaches to therapy for which suitable video recordings are available. For example, if recordings of full sessions of cognitive behavioral therapy were available, then the same analyses would be possible. These analytic tools may also be helpful for training, for helping new therapists become more aware of what they are doing (and can do). Moreover, there are myriad other features of therapeutic communication than the two we examined here, which are also amenable to study under the microscope of this technique. When we focus more and more closely on communication; we may come to see psychotherapy less in terms of nouns (e.g., empathy, insight) and more in terms of verbs, as something therapist and client "do" together.

\section{NOTE}

1. It may initially appear that this analysis violated the assumption of independence for Chi-square. However, statistical dependence means that the mere occurrence of one event necessarily determines the probability of other events. In our data there is no reason why, having made a positive utterance, the therapist would have to make more or fewer such utterances later-unless this pattern was the therapist's style, which is the phenomena under study here.

\section{REFERENCES}

American Association for Counseling and Development (Producer). (1980). The Struggle for Self Acceptance: The Inner World of Counseling, Session 1/with Carl Rogers [Motion Picture].

American Psychological Association (Producer). (1994). Client Centered Therapy: Nathaniel J. Raskin. [Motion Picture]. (Available on the American Psychological Association website: http://www.apa.org/videos/4310250.html.

Bavelas, J.B., McGee, D., Phillips, B., \& Routledge, R. (2000). Microanalysis of communication in psychotherapy. Human Systems, 11, 47-66.

Brief Family Therapy Center (Producer). (2004). An Interview with Insoo Kin Berg"I'm Glad to be Alive..." Working with Suicidal Youth [Motion picture]. (Available from the Brief Family Therapy Center, Milwaukee, WI).

Clark, H.H. (1996). Using language. Cambridge, England: Cambridge University Press.

De Jong, P. \& Berg, I.K. (2002). Interviewing for solutions (2nd ed). Pacific Grove, CA: Brooks/Cole.

de Shazer, S. (1985). Keys to solutions in brief therapy. New York, NY: Norton.

de Shazer, S. (1990). [Restricted videotaped therapy session with Steve de Shazer] Unpublished motion picture.

de Shazer, S. (1994). Words were originally magic. New York, NY: Norton.

Farber, B.A., Brink, D.C., \& Raskin, P.M. (Eds.). (1996). The psychotherapy of Carl Rogers: Case and commentary. New York: NY The Guilford Press.

Garfinkl, H. \& Sacks, H. (1970). On formal structures of practical actions. In J.C. McKinney \& E.A. Tiryakian (Eds.), Theoretical sociology (pp. 337-366). New York, NY: Appleton-Century-Crofts.

Heritage, J. \& Watson, R. (1979). Formulations as conversational objects. In G. Pasathas (Ed.), Everyday language: Studies in ethnomethodology (pp: 123-162). New York: Irvington.

Kazdin, A.E. \& Nock, M.K. (2003). Delineating mechanisms of change in child and adolescent therapy: Methodological issues and research recommendations. Journal of Child Psychology and Psychiatry, 44, $1116-1129$.

McGee, D., Del Vento, A., \& Bavelas, J.B. (2005). An interactional model of questions as therapeutic interventions. Journal of Marital and Family The rapy, 31, 371-384.

Rogers, C.R. (1965). Client-centered therapy: Its current practice, implications, and theory. Boston, MA: Houghton Mifflin Company.

Tomori, C. (2004). A microanalysis of communication in psychotherapy: Lexical choice and therapy direction. Unpublished Honours thesis, Department of Psychology, University of Victoria.

doi: $10.1300 / J 085 v 18 \mathrm{n} 03 \_03$ 